\section{Cureus}

Received 05/24/2019

Review began 05/29/2019

Review ended 06/03/2019

Published 06/10/2019

\section{(c) Copyright 2019}

Iftikhar et al. This is an open access article distributed under the terms of the Creative Commons Attribution License CC-BY 3.0., which permits unrestricted use, distribution, and reproduction in any medium, provided the original author and source are credited.

\title{
Pernicious Anemia Presenting as Non-ST- elevated Myocardial Infarction and Depression
}

\author{
Hassaan Iftikhar ${ }^{1}$, Maryam Saleem ${ }^{2}$, Anand Kaji ${ }^{1}$ \\ 1. Internal Medicine, St. Francis Medical Center, Seton Hall University, Trenton, USA 2. Internal \\ Medicine, Waterbury Hospital, Waterbury, USA
}

$\square$ Corresponding author: Hassaan Iftikhar, hassaan213@gmail.com

Disclosures can be found in Additional Information at the end of the article

\section{Abstract}

Pernicious anemia (PA) is a common cause of megaloblastic anemia throughout the world, especially in Northern European whites. This disease is characterized by the deficiency of vitamin B12 due to the presence of anti-intrinsic factor and anti-parietal cell antibodies which inhibit the absorption of the vitamin B12. In cases of severe vitamin B12 deficiency, patients can suffer debilitating complications such as described in our case.

Categories: Cardiology, Internal Medicine, Oncology

Keywords: nstemi, depression, depression, pernicious anemia, b12, atrophic gastritis

\section{Introduction}

Vitamin B12 is a coenzyme required for deoxyribonucleic acid (DNA) synthesis [1], and its deficiency can lead to erythropoietic hemolysis in bone marrow, the formation of macrocytes, and hypersegmentation of neutrophils. Most cases of vitamin B12 deficiency are due to malabsorption rather than dietary deficiency. It can present with symptoms of anemia and/or neurologic dysfunction. It is a critical diagnosis as it is a reversible cause of anemia and can prevent transfusions. We describe an unusual case of vitamin B12 deficiency anemia presenting as non-ST-elevated myocardial infarction (NSTEMI) with depressive symptoms

\section{Case Presentation}

This study includes a 73-year-old female with the past medical history of hypertension, hypothyroidism, and coronary artery disease (previous cardiac catheterization showed 99\% stenosis in the right coronary artery and stent placement in the circumflex artery) who presented with chest pain for one day. She described the chest pain as constant, progressive, non-radiating, 5/10 in intensity, and pressure-like in character with no aggravating or alleviating factors. She endorsed associated symptoms of increasing shortness of breath and generalized weakness. Her walking capacity had decreased from two blocks at baseline to 15 steps. She also described her diet mainly being as tea, crackers, canned food, bread, and cheese. The review of systems was significant for depressed mood and low energy. She denied any history of gait disturbances, weakness, memory loss, dizziness, lightheadedness, syncope, cough, difficulty in maintaining posture, numbness or tingling in feet, bleeding, and any gastrointestinal surgery. Family history was significant for laryngeal carcinoma in the father. The social history was significant for smoking one pack per day for 20 years which she had quit 30 years ago, and she denied any alcohol or illicit drug use. She was not taking any home medications. 


\section{Cureus}

Her physical exam on admission including vitals was normal except for the remarkable findings of pale conjunctiva and shiny tongue.

Her complete blood count is described in Table 1.

\begin{tabular}{|lll|}
\hline Test & Result & Reference range \\
\hline Complete Blood Count & & \\
Hemoglobin (Hb) & $4.9 \mathrm{~g} / \mathrm{dl}$ & $12-16 \mathrm{~g} / \mathrm{dl}$ \\
Hematocrit (HCT) & $13.9 \%$ & $37-47 \%$ \\
Mean corpuscular volume(MCV) & $142.2 \mathrm{fL}$ & $78-102 \mathrm{fL}$ \\
Red cell distribution width (RDW) & $24.4 \%$ & $11.5-14.5 \%$ \\
Platelets & 66000 thou/L & $130-400$ thou/L \\
Corrected Reticulocyte count & $1.4 \%$ & \\
White blood cells (WBC) & 5.2 thou/L & $4.8-10.8$ thou/L \\
\hline
\end{tabular}

\section{TABLE 1: Complete blood count}

The iron panel is described in Table 2 .

\begin{tabular}{|c|c|c|}
\hline Test & Result & Reference range \\
\hline \multicolumn{3}{|l|}{ Iron Panel } \\
\hline Serum Iron & 37 mg/dl & $37-145 \mathrm{mg} / \mathrm{dl}$ \\
\hline Transferrin & $138 \mathrm{mg} / \mathrm{dl}$ & $200-360 \mathrm{mg} / \mathrm{dl}$ \\
\hline Ferritin & $144 \mathrm{mg} / \mathrm{dl}$ & 13-150 mg/dl \\
\hline Transferrin saturation & $19 \%$ & \\
\hline
\end{tabular}

\section{TABLE 2: Iron panel}

Other miscellaneous laboratory findings are given in Table 3. 


\section{Cureus}

\begin{tabular}{|c|c|c|}
\hline Test & Result & Reference range \\
\hline \multicolumn{3}{|l|}{ Miscellaneous } \\
\hline Vitamin B12 level & $35 \mathrm{pg} / \mathrm{ml}$ & $211-946 \mathrm{pg} / \mathrm{ml}$ \\
\hline Folic acid & $16 \mathrm{ng} / \mathrm{ml}$ & $>4.1 \mathrm{ng} / \mathrm{ml}$ \\
\hline Lactate dehydrogenase (LDH) & $1444 \mathrm{U} / \mathrm{L}$ & 135-214 U/L \\
\hline Methylmalonic acid level & $>5.00$ umol/L & $<0.4$ umol/L \\
\hline Total Bilirubin & $1.5 \mathrm{mg} / \mathrm{dl}$ & $<1 \mathrm{mg} / \mathrm{dl}$ \\
\hline
\end{tabular}

\section{TABLE 3: Miscellaneous laboratory results}

On further workup, her peripheral smear showed hypersegmented neutrophils, the intrinsic factor antibody was negative, but the parietal cell antibody was positive. Troponins were elevated at 0.78 followed by 0.92 . EKG showed new onset T-wave inversions in lead I, aVL, V5, and V6. 2D echo revealed a drop in the EF from $55 \%$ to $25 \%$ in two years. As such, she was diagnosed with NSTEMI and depressed mood likely secondary to pernicious anemia (PA).

Over the hospital course, the patient received three units of red blood cells and daily intramuscular injections of 1000 micrograms of cyanocobalamin which improved the hemoglobin to $8.6 \mathrm{~g} / \mathrm{dl}$ and decreased the MCV to 103.5 . Her chest pain resolved significantly and her depressive symptoms were ameliorated. The plan on discharge was to give the patient vitamin B12 shots weekly and outpatient esophagogastroduodenoscopy (EGD) with monitoring of serial CBCs. The patient was made appointments to follow up with her gastroenterologist, hematologist, and primary care physician.

\section{Discussion}

PA is the most common cause of megaloblastic anemia throughout the world especially in Northern European whites but the incidence is also increasing in non-northern European or Africans. Multiple cases of PA associated with autoimmune hemolytic anemia have been described in the literature [1-2]. However, there have not been cases of PA leading to NSTEMI in the literature. Vitamin B12 is found in animal meat, shellfish, liver, and dairy. The normal absorption of vitamin B12 involves binding to intrinsic factor (IF) and getting absorbed in the terminal ileum. However, in PA, patients have anti-parietal cell antibodies (Ab) and/or anti-IF $\mathrm{Ab}$, which prevent the production of IF and inhibit B12 binding to IF and absorption, respectively [2-3]. The tea and toast diet of old age can exacerbate the deficiency. However, most cases of vitamin B12 are due to malabsorption rather than a dietary deficiency. At the level of bone marrow, vitamin B12 deficiency causes ineffective erythropoiesis leading to the formation of megaloblasts, hypersegmented neutrophils, and early destruction of erythroblasts by apoptosis causing elevated lactate dehydrogenase (LDH), bilirubin, and low reticulocyte count [1]. Pancytopenia may occur as well. PA is associated with autoimmune atrophic gastritis which has a potential of causing intestinal type gastric metaplasia. For diagnostic purposes, an important point to note is that the low serum vitamin B12 levels are not as helpful as serum methylmalonic acid levels which are closer to representing tissue vitamin B12 levels [4]. Anti-IF $\mathrm{Ab}$ is highly specific but not sensitive but anti-parietal cell antibodies are not as sensitive or specific [5-6]. 
In addition to the hematologic manifestations, PA can have neurologic symptoms including but not limited to subacute combined degeneration of spinal cord, demyelination of dorsal column leading to ataxia, peripheral neuropathy, and psychiatric complications [7]. Also, it has been reported in the literature that the degree of bone marrow suppression is inversely related to neurologic symptoms and significant anemia rarely presents in coexistence with neurologic symptoms [8-9].

The pathophysiology of myocardial ischemia in the setting of vitamin B12 deficiency would be caused by the mismatch in myocardial oxygen supply and demand from the developing anemia in face of low B12. This is especially true for patients with atherosclerotic coronary artery disease in which severe anemia can present as chest pain and decreased exercise tolerance [5]. This gives the picture of type II myocardial infarction which is typical of demand ischemia [10]. Our patient presented with a unique complication of PA which has not been reported in literature earlier. Patients can be treated with oral vitamin B12 in doses of 1000-2000 ug or parenteral forms by 50-100 ug once weekly until the deficiency is corrected and afterward, monthly injections $[5,11]$.

\section{Conclusions}

Our case describes a unique scenario where PA led to myocardial ischemia in the absence of any other cause. It also lays emphasis on the importance of early recognition of PA, especially in the elderly population who are at higher risk due to tea and toast diet in addition to autoimmune pathophysiology. It also describes the treatment of PA and the potential downstream complications such as myocardial infarction and depression which might develop if the condition goes undiagnosed for a long time.

\section{Additional Information \\ Disclosures}

Human subjects: Consent was obtained by all participants in this study. Conflicts of interest: In compliance with the ICMJE uniform disclosure form, all authors declare the following:

Payment/services info: All authors have declared that no financial support was received from any organization for the submitted work. Financial relationships: All authors have declared that they have no financial relationships at present or within the previous three years with any organizations that might have an interest in the submitted work. Other relationships: All authors have declared that there are no other relationships or activities that could appear to have influenced the submitted work.

\section{References}

1. Todo S, Okamoto K, Sugimoto T, et al.: A case of pernicious anemia requiring differential diagnosis of autoimmune hemolytic anemia complication. Oxf Med Case Reports. 2017, 2017:172-175. 10.1093/omcr/omx053

2. Yeruva SLH, Manchandani RP, Oneal P : Pernicious anemia with autoimmune hemolytic anemia: a case report and literature review. Case Rep Hematol. 2016, 2016:1-4. 10.1155/2016/7231503

3. Stabler SP, Allen RH: Vitamin B12 deficiency as a worldwide problem . Annu Rev Nutr. 2004, 24:299-326. 10.1146/annurev.nutr.24.012003.132440

4. Osborne D, Sobczyńska-Malefora A: Autoimmune mechanisms in pernicious anaemia \& thyroid disease. Autoimmun Rev. 2015, 14:763-768. 10.1016/j.autrev.2015.04.011

5. Green R: Vitamin B12 deficiency from the perspective of a practicing hematologist . Blood. 2017, 129:2603-2611. 10.1182/blood-2016-10-569186

6. Carmel R: Reassessment of the relative prevalences of antibodies to gastric parietal cell and to intrinsic factor in patients with pernicious anaemia: influence of patient age and race. Clin Exp Immunol. 1992, 89:74-77. 10.1111/j.1365-2249.1992.tb06880.x 


\section{Cureus}

7. Carmel R, Green R, Rosenblatt DS, Watkins D: Update on Cobalamin, Folate, and Homocysteine . Hematology Am Soc Hematol Educ Program. 2003, 1:62-81.

10.1182/asheducation-2003.1.62

8. Rannelli L, Watterson R, Pandya R, Leung AA: Vitamin B12 deficiency with combined hematological and neuropsychiatric derangements: a case report. J Med Case Rep. 2014, 8:277. 10.1186/1752-1947-8-277

9. Healton EB, Savage DG, Brust JC, Garrett TJ, Lindenbaum J: Neurologic aspects of cobalamin deficiency. Medicine (Baltimore). 1991, 70:229-245.

10. Thygesen K, Alpert JS, Jaffe AS, et al.: Fourth universal definition of myocardial infarction. Circulation. 2018, 138:618-651. 10.1161/CIR.0000000000000617

11. Hathcock JN, Troendle GJ: Oral cobalamin for treatment of pernicious anemia?. JAMA. 1991, 265:96-97. 10.1001/jama.1991.03460010096040 